\title{
MEASURING SURFACE DEFORMATION IN GLACIER RETREATED AREAS BASED ON PS-INSAR - GELADANDONG GLACIER AS A CASE STUDY
}

\author{
B. Mohamadi, T. Balz*
}

State Key Laboratory of Information Engineering in Surveying, Mapping and Remote Sensing, Wuhan University, People's Republic of China (bh.mo, balz)@whu.edu.cn.

KEY WORDS: China, Glacier retreat, InSAR, Paraglacial Slope Failure (PSF), Qinghai-Tibetan Plateau (QTP)

\begin{abstract}
:
Glaciers are retreating in many parts of the world as a result of global warming. Many researchers consider Qinghai-Tibetan Plateau as a reference for climate change by measuring glaciers retreat on the plateau. This retreat resulted in some topographic changes in retreated areas, and in some cases can lead to geohazards as landslides, and rock avalanches, which is known in glacier retreated areas as paraglacial slope failure (PSF). In this study, Geladandong biggest and main glacier mass was selected to estimate surface deformation on its glacier retreated areas and define potential future PSF based on PS-InSAR technique. 56 ascending and 49 descending images were used to fulfill this aim. Geladandong glacier retreated areas were defined based on the maximum extent of the glacier in the little ice age. Results revealed a general uplift in the glacier retreated areas with velocity less than $5 \mathrm{~mm} / \mathrm{year}$. Obvious surface motion was revealed in seven parts surround glacier retreated areas with high relative velocity reached $\pm 60 \mathrm{~mm} /$ year in some parts. Four parts were considered as PSF potential motion, and two of them showed potential damage for the main road in the study area in case of rock avalanche into recent glacier lakes that could result in glacier lake outburst flooding heading directly to the road. Finally, further analysis and field investigations are needed to define the main reasons for different types of deformation and estimate future risks of these types of surface motion in the Qinghai-Tibetan Plateau.
\end{abstract}

\section{INTRODUCTION}

Mountain glaciers are playing an important role in climatology, hydrology, and mountains topography changes. Glaciers on the Tibetan Plateau are considered as a major indicator of Earth's climate change due to their sensitivity to global warming ( $\mathrm{Lu}$ et al., 2002).

Glaciers locations in remote areas make the regular survey a difficult task as it is costly and time-intensive. Hence, remote sensing techniques offer the opportunity to obtain detailed information of glaciers' physical characteristics changes over time in wide coverage areas (Lu et al., 2002).

Among other remote sensing techniques, Differential InSAR (D-InSAR) and intensity offset tracking techniques were successfully used worldwide in many studies to monitor glacier changes over time (Sánchez-Gámez and Navarro, 2017). Whereas, very few studies have been conducted to monitor glaciers using Persistent Scatterer Interferometric Synthetic Aperture Radar (PS-InSAR) due to a lack of coherent points on the ice, and the velocity of the motion often being too fast (Shi, 2012). However, PS-InSAR technique could be an excellent tool for glacier retreat related deformation estimation and its related hazards detection, as many persistent scatter points can be found due to the higher coherence in these areas.

PS-InSAR is well-known in its capability to detect surface deformation related geohazards. However, PS-InSAR requires a high density of stable interferometric points, which can typically not be found outside of urban areas. However, glacier retreat areas (not the ice though) are an exception, as we can find a big amount of rocks and boulders and less vegetation.

Under certain geological conditions, the loss of ice volume in glacier retreat regions could cause instability of the bedrock and lead to trigger landslides and rock avalanches due to the development of a deep-seated gravitational slope deformation 'DSGSD' (Martinotti et al., 2011).

The unloading of the melting ice causes loss of confinement for the slope, which leads to stress redistribution in the bedrock, and, higher stress levels can come to exceed the rock mass strength which calls paraglacial slope failure 'PSF' (Ballantyne and Stone, 2013). With a high temporal resolution, enough coherent points can be found, that allowing the use of PS-InSAR for paraglacial deformation detection and its related hazards.

To the best of our knowledge, no research in China was conducted to study glacier retreat areas' bedrock deformation. Whereas, PSF was studied in other countries including Canada (Holm et al., 2004), Scotland (Ballantyne and Stone, 2013), and Switzerland (Persson 2010).

In this study, PS-InSAR has been applied on Geladandong Peak using Sentinel 1A/B data (Copernicus, 2018), to estimate deformation on glacier retreated areas. The availability of Sentinel-1 (S1) data gives us the opportunity to contribute a big number of images in the PS-InSAR analysis, thanks to its shorter temporal baseline (twelve days for one sensor full cycle $\mathrm{S} 1 \mathrm{~A}$, or $\mathrm{S} 1 \mathrm{~B}$; and six days' repetitive acquisition for both sensors data). That advantage was not available for scientific research before. Now, we have accessibility to tensto-hundreds of images for any study area worldwide. This advantage results in more coherent points due to the shorter temporal baseline, and hence, higher velocities can be estimated based on that

\footnotetext{
* Corresponding author
} 


\section{STUDY AREA}

Geladandong is the highest peak of Tanggula Mountains and the source region of the Yangtze river. It is located in the central Qinghai-Tibet Plateau (QTP) between $90^{\circ} 42^{\prime} \sim 91^{\circ} 41^{\prime} \mathrm{E}$ and $33^{\circ} .02^{\prime} \sim 33^{\circ} 41^{\prime} \mathrm{N}$. Geladandong Peak altitude is between $5200 \mathrm{~m}$ and $6621 \mathrm{~m}$, and the total glacial area is about 1000 $\mathrm{km}^{2}$, separated in three main masses, beside many other small size glaciers (Figure 1). It is believed that the Geladandong glaciers are retreating due to the increase in summer air temperature. However, this retreating is at lower rates compares to other glaciers in the QTP (Lu et al., 2002; Ye et al., 2006).

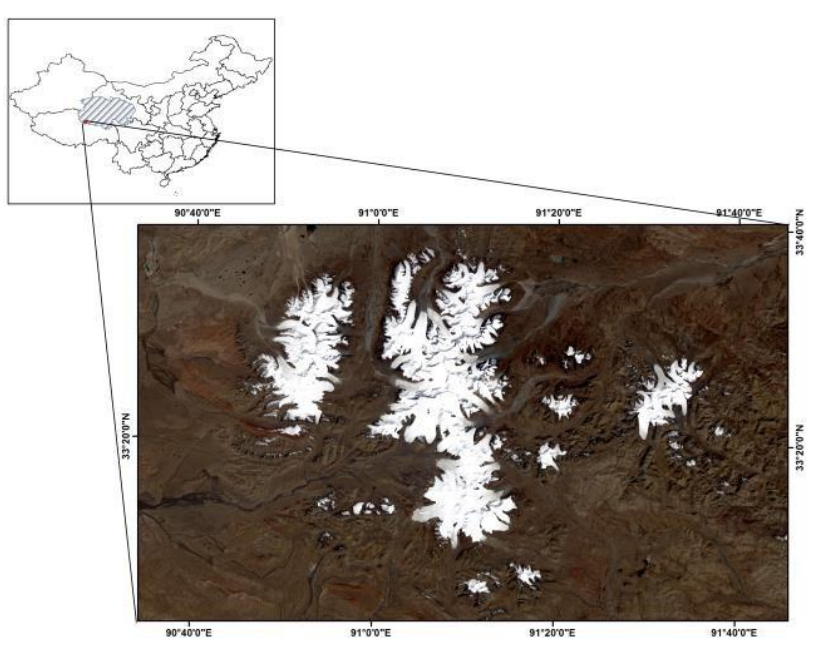

Figure 1. Geladandong location

\section{METHODOLOGY}

\subsection{Define Area of Interest}

In this study, we have selected the main glacier in the Geladandong Peak to estimate surface deformation in its retreated areas and recognize potential glacial slope failure. To define the glacier retreated areas, we selected the area between the two outlines of recent glacier extent and its maximum extent in the Little Ice Age (LIA). The LIA is the global cooling period between the sixteenth century and the end of the nineteenth century. In the recent geological history, glaciers worldwide have reached their widest area coverage during this period ( $\mathrm{Li}$ and $\mathrm{Li}, 2014$ ).

Since there are insufficient studies on the QTP glaciers before mid of the twentieth century that we could depend on to define the extent of Geladandong glacier during the LIA; we used a Landsat- 8 image to define the maximum extent of the glacier during that period. Remote sensing was successfully used in many previous studies to define the spatial extent of glacier retreated areas since the LIA (including $\mathrm{Lu}$ et al. 2002 in Geladandong). This procedure is based on the detection of geomorphological evidence of glacial landforms such as terminal moraines. Besides, slope and elevation extracted from digital elevation models (DEMs). Also, vegetation cover which can be used to distinguish the LIA moraine extent based on the low vegetation density on these retreated areas compared to surrounding vegetation coverage ( $\mathrm{Li}$ and $\mathrm{Li}, 2014$; Loibl et al., 2014).

We selected a Landsat- 8 image acquired in the late of August 2017 as the end of the melting season, and before the starting of the new snow precipitation season to detect vegetation coverage and avoid any false interpretation of fresh snow in the study area to define the recent glacier extent. The maximum extent of Geladandong glacier during LIA was manually digitized based on this image with the support of SRTM 1-arc extracted elevation and slope data as represented in Figure 2. Some other Landsat- 7 and Landsat- 8 images were also used to support the glacier extent extraction in cloudy and shaded areas of the main used image.
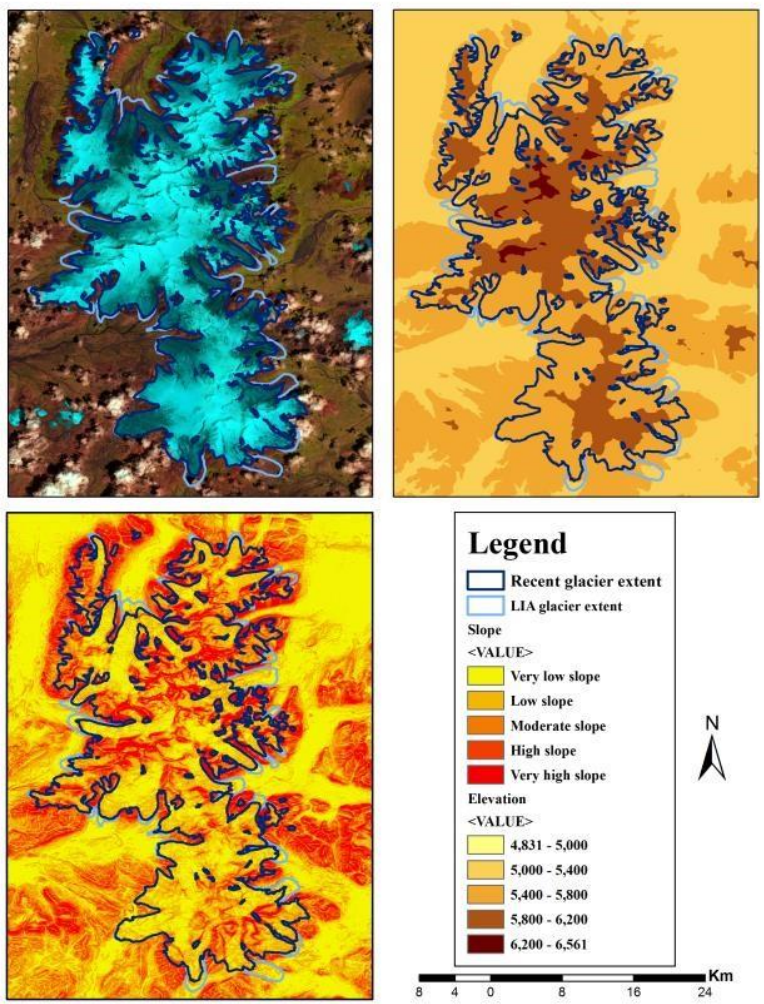

Figure 2. Recent and LIA maximum glacier extent of the Geladandong main glacier.

\subsection{Paraglacial Deformation Detection}

The PS-InSAR technique, which was developed by Ferretti et al. (2000), can be used effectively to detect surface deformation in glacier retreated areas. By using multiple images, stable point-scatterers can be identified in the data. Forming a network between these stable and persistent scatterers (PS), the influences of the atmosphere, errors from the topography, and the deformation signal can be separated by spatiotemporal filtering. This requires a rather high PS density and a large amount of data.

In this study, we used SarProZ ${ }^{\odot}$ software (Perissin et al., 2013; SarProZ Development Team, 2017) to utilize 56 images in ascending and 49 images in descending orbits of Sentinel1A/B data between 2015 and 2017 (Copernicus, 2018), as represented in Table 1, to estimate glacier retreat area's bedrock motion in the Geladandong glacier retreated areas by using PS-InSAR technique.

The processing of cross-heading orbits allows to overcome the limitation of the line-of-sight measurements and retrieve true $3 \mathrm{D}$ deformation vectors, by combining the deformation vectors from both orbits (Liao et al., 2013). This advantage gives us the opportunity to define vertical and horizontal deformation in these areas. 


\begin{tabular}{|l|c|c|c|}
\hline Orbit & \multicolumn{2}{|c|}{ Sensor } & Total \\
\hline & S1A & S1B & \\
Ascending & 56 & - & 56 \\
Descending & 42 & 7 & 49 \\
\hline
\end{tabular}

Table 1. Processed images

The PS-InSAR process is started by defining an appropriate master image for each stack and then extract the slave images based on the defined extent of the master image. Next step is the coregistration of slave images to the master image. Sentinel-1 has a high precision orbit, which gives a good result in PS-InSAR. However, the standard acquisition mode of S1 data, which is the TOPS mode, requires more precise coregistration compared to traditional Stipmap based data

'9/10000th of a pixel instead of just 1/10th' (Yague-Martinez et al., 2017).

After the coregistration process is finished, the amplitude stability index is estimated for the whole stack. After radarcoding of the DEM, we start to estimate the atmospheric phase screen (APS). In the APS estimation process, we selected the star graph image combination and used amplitude stability index with a threshold of 0.25 as a sparse points selection parameter. Then, corrected for linear trend and height by \pm 60 in both parameters after a process of trial-and-error to obtain the most precise results. Then, we selected the appropriate reference point for deformation estimation, and finally estimated the APS with inverted parameters option.

The final step is processing the multi-image sparse points. We used a threshold of 0.3 for the amplitude stability index and an identical parameter range from linear trend and height of APS estimation. This process estimated the velocity of each PS point along the study period in each image based on the reference point, after isolating noise of atmospheric and topographic effects to produce a velocity map for Geladandong Peak.

The velocity of extracted PS points was imported to $\mathrm{ArcGIS}^{\odot}$ 10.5 software (ArcGIS Development Team, 2016), to overlay glacier retreated areas and surroundings. PS with a temporal coherence threshold of 0.7 and above were used as the final PSInSAR deformation estimation results. Results of each orbit (ascending and descending) were divided into two spatial layers: points on glacier retreated areas, and points within one kilometer from glacier retreated areas.

\section{RESULTS}

\subsection{Deformation on Glacier Retreated Areas}

The overall average of surface deformation on the Geladandong main glacier retreated areas is less than $5 \mathrm{~mm} /$ year according to ascending and descending orbits data analysis; it is 4.18 $\mathrm{mm} /$ year in ascending and $2.83 \mathrm{~mm} /$ year in descending. These values could be considered as a reference for a slight uplift on glacier retreated areas.

Average deformation on glacier retreated areas was estimated for each glacier tongue individually (Figure 3). We classified 45 different glaciers retreated areas. Average deformation is recognized as uplift (positive deformation values in both ascending and descending orbits) in 28 different retreated areas (about $62.2 \%$ of glacier retreated areas), with relative velocity between $0.7 \mathrm{~mm}$ and $5.45 \mathrm{~mm}$ per year.

Five glaciers retreated areas (11.1\%) showed active subsidence (having negative velocity values in both orbits) with higher velocity compared to those areas having uplift deformation. The highest velocity was found in a small part of glacier retreated area, which shown in figure 3-D with an average velocity of $-21 \mathrm{~mm} /$ year in ascending and $-9.8 \mathrm{~mm} / \mathrm{year}$ in descending orbit. Figure 3-A shows another relative high subsidence with a velocity of $-19 \mathrm{~mm}$ and $-4.1 \mathrm{~mm}$ per year in ascending and descending respectively. Other subsidence glacier retreated areas where represented lower relative velocities between $-0.8 \mathrm{~mm}$ and $-15.6 \mathrm{~mm}$ per year (Figure 3-B as an example).

Ten glacier retreated areas (22.2\%) showed horizontal motion during the study period (having positive velocity values in one orbit and negative values in the other orbit). These areas have relative velocity between $-13.1 \mathrm{~mm}$ and $8.54 \mathrm{~mm}$ per year (Figure 3-C as an example). Also, two other glaciers retreated areas did not have enough coherent points for conclusive analysis.
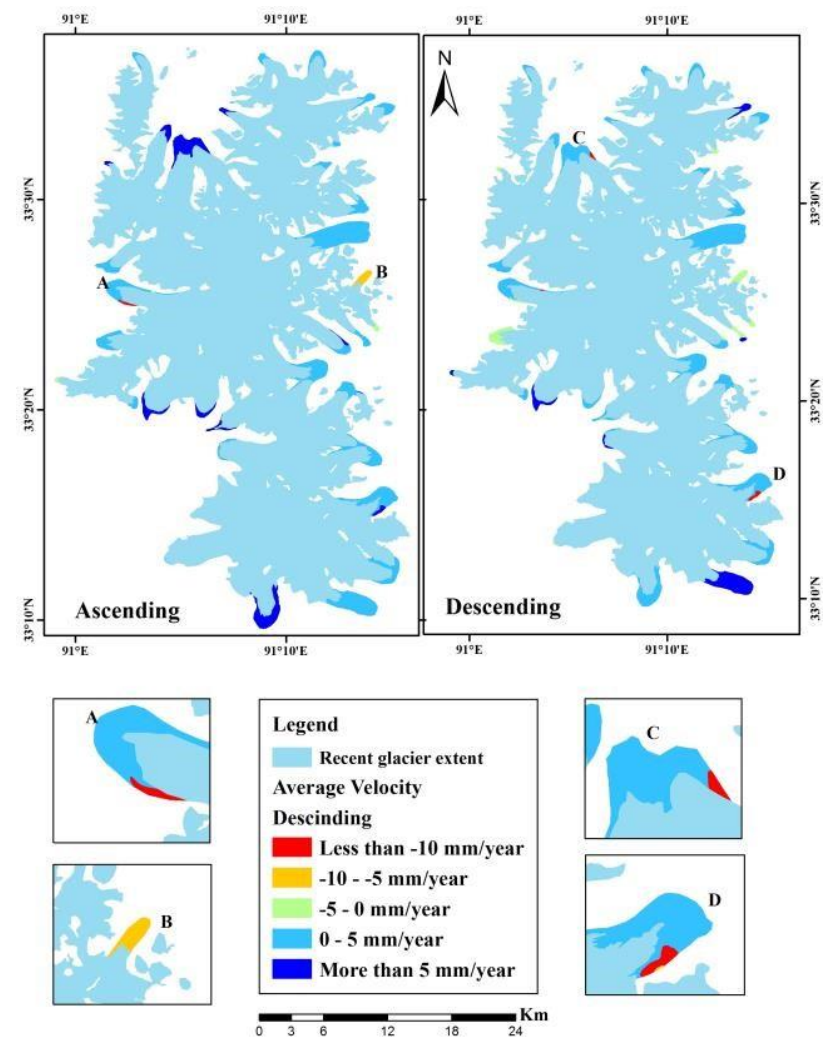

Figure 3 . The average velocity on glacier retreated areas

\subsection{Deformation of High Slope Areas Surrounding Glacier Retreated Areas.}

PS points on glacier retreat surrounding areas were analyzed visually for serious surface deformation. Seven parts showed obvious surface deformation within the study area. They are shown in figure 4. Some of these areas are small in space and number of PS points such as those shown in figure $4 \mathrm{C}, \mathrm{D}$, and F. Those may not be considered as a potential PSF at the moment. However, those areas show some higher velocities as $-32.14 \mathrm{~mm}$ in ascending and $-11.96 \mathrm{~mm} /$ year in descending for area represented in figure $4 \mathrm{C},-27.58 \mathrm{~mm}$ in ascending and $17.21 \mathrm{~mm} /$ year in descending for area represented in $4 \mathrm{D}$, and $21.02 \mathrm{~mm}$ and $-12.15 \mathrm{~mm} /$ year for area represented in figure $4 \mathrm{~F}$ in ascending and descending respectively.

Horizontal displacement was detected in areas shown in figures $4 \mathrm{~A}$, and $4 \mathrm{~F}$ with an average deformation of $21.17 \mathrm{~mm} /$ year in ascending and $-31.55 \mathrm{~mm} /$ year in descending for the area in figure $4-\mathrm{A}$, and $19.86 \mathrm{~mm}$ in ascending and $15.76 \mathrm{~mm} /$ year in descending for the area shown in figure $4-\mathrm{F}$. 
Figure 4-E showed deformation along the edge of the glacier extent in the LIA. The eastern part of the glacier retreated area boundary showed horizontal motion with $15.75 \mathrm{~mm} /$ year in ascending and $-23 \mathrm{~mm} /$ year in the descending orbit. Whereas the north-eastern and southern edges of this glacier retreated area have subsidence with a velocity of $-1.96 \mathrm{~mm}$ and -14.33 $\mathrm{mm} /$ year in ascending and $-20.79 \mathrm{~mm}$ and $6.12 \mathrm{~mm} /$ year in descending respectively.

The highest and biggest surface motion was detected in the areas represented in figure $4-\mathrm{B}$ in the eastern part of the Geladandong glacier, reaching velocities up to $\pm 60 \mathrm{~mm} /$ year. Both subsidences in the northern part of figure 4-B and horizontal deformation on the other are detected with surface velocity average of $-17.67 \mathrm{~mm} /$ year in ascending and -21.35 $\mathrm{mm} / \mathrm{year}$ in descending for the northern part. Whereas, horizontal displacement velocity average in this area was estimated by $-25.52 \mathrm{~mm} /$ year in ascending and $17.82 \mathrm{~mm} /$ year in descending orbit.

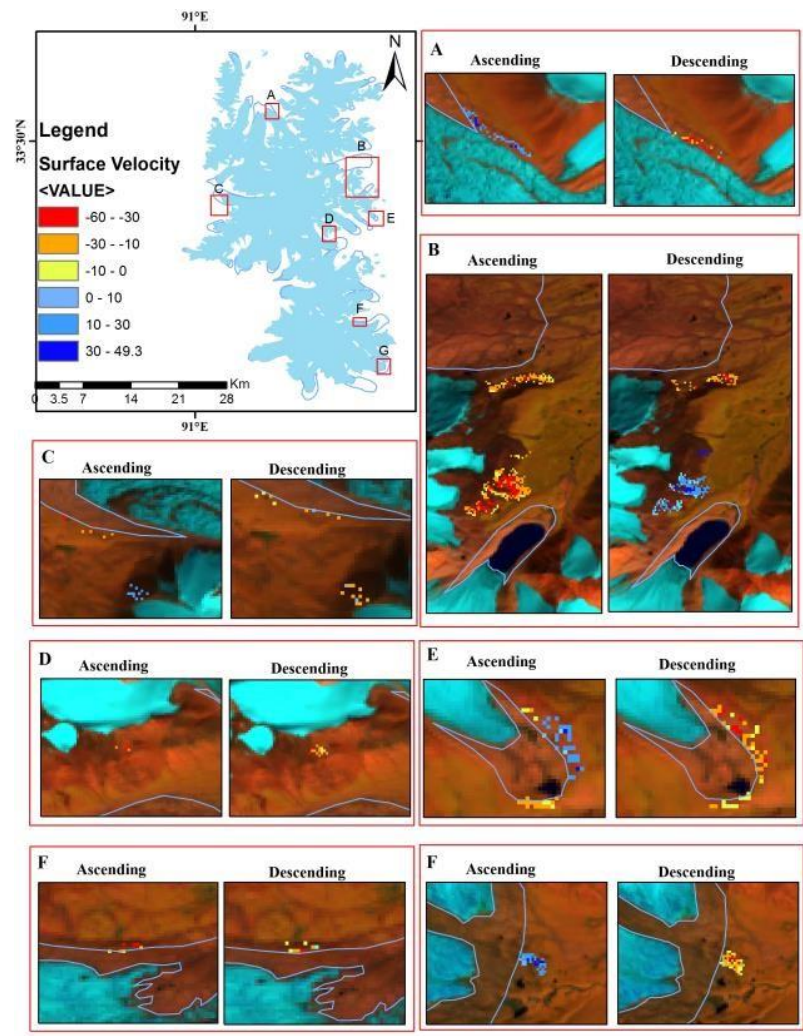

Figure 4. Surface deformation on glacier retreated surrounding areas.

Deformation in areas shown in figure 4-A, B, E, and F could be considered as deformation for potential PSFs in the near future based on their velocity, area, and PS points density. The highest PSF possibility was considered in Figure 4B, E, F, and A respectively. Surface motion severity is serious in areas of figure 4-B, and $\mathrm{E}$ due to the existence of glacier lakes on the glacier tongues bottom, which could lead to a glacier lake outburst flooding in case of rock avalanche into those lakes. Which, could cause damage to the main road (G109) that cross beside Geladandong Peak in the east of the glacier in case of the flooding hiding directly to the road.

\section{CONCLUSION}

The advantage of Sentinel-1 big data was used in this study to estimate surface deformation over glacier retreated areas and detect potential PSF on its surrounding areas. 56 ascending and 49 descending images were analysed in $\mathrm{SarProZ}^{\odot}$ software. Results revealed a slight uplift in Geladandong retreated areas with velocity less than $\pm 5 \mathrm{~mm}$ per year. Some retreated areas revealed subsidence and others represented horizontal motions. Potential future PSF estimated surrounding some LIA glacier extent with surface motion reached $\pm 60 \mathrm{~mm} /$ year in some parts on the east of the glacier. This study result is introducing PSInSAR technique as a tool for PSF early warning. In Geladandong Peak, more investigation is needed to explain surface motion detected in this study in glacier retreated areas and LIA maximum extent edges. Hence, we are aiming to extent this study in our future work to fulfil this aim. In addition, the serious surface motion that detected close to some glacier lakes in this study opening the question of potential glacier lake outburst flooding as a result of PSF in Qinghai-Tibetan Plateau, which will also be considered in our future work too.

\section{ACKNOWLEDGEMENTS}

The work presented here was supported by the Natural Science Foundation of China (Grant No.61331016). The authors would like to thank Daniele Perissin for providing the SarProZ software to support this research.

\section{REFERENCES}

Ballantyne, C.K., and Stone, J.O., 2013. Timing and periodicity of paraglacial rock-slope failures in the Scottish Highlands. Geomorphology,186 (186), pp. 150-161.

Copernicus, 2018. Sentinel-1 2015-2017 data processed by ESA, retrieved from https://earth.esa.int (5 January 2018).

ESRI Development Team, 2016. ArcGIS Desktop: Release 10.5. Redlands, CA: Environmental Systems Research Institute.

Ferretti, A., Prati, C., and Rocca, F., 2000. Analysis of Permanent Scatterers in SAR interferometry. Geoscience and Remote Sensing Symposium, 2000. Proceedings. IGARSS 2000. IEEE 2000 International, Vol.39 (2), pp.761-763.

Holm, K., Bovis, M., and Jakob, M., 2004. The landslide response of alpine basins to post-little ic,e age glacial thinning and retreat in southwestern British Columbia. Geomorphology, 57(3), pp. 201-216.

Li, Y., and Li, Y., 2014. Topographic and geometric controls on glacier changes in the central tienshan, China, since the little ice age. Annals of Glaciology, 55(66), pp. 177-186.

Liao, M., Zhang, L., Balz, T., Shi, X., and Tantianuparp, P., 2013. Multi-Orbit Ps-Insar for Landslide Monitoring in Three Gorges Area (Invited). American Geophysical Union 2013 Fall Meeting.

Loibl, D., Lehmkuhl, F., and Grießinger, J., 2014. Reconstructing glacier retreat since the little ice age in se Tibet by glacier mapping and equilibrium line altitude calculation. Geomorphology, 214(2), pp. 22-39. 
Lu, A.X., Yao, T., Liu, S., Ding, L., and Gang, L.I., 2002. Glacier change in the geladandong area of the Tibetan plateau monitored by remote sensing. Journal of Glaciolgy \& Geocryology, 24(5), pp. 559-562 (In Chinese).

Martinotti, G., Giordan, D., Giardino, M., and Ratto, S., 2011. Controlling factors for deep-seated gravitational slope deformation (dsgsd) in the aosta valley (nw alps, Italy). Geological Society London Special Publications, 351, pp. 113-131.

Sánchez-Gámez, P., and Navarro, F., 2017. Glacier surface velocity retrieval using d-insar and offset tracking techniques applied to ascending and descending passes of sentinel-1 data for southern ellesmere ice caps, Canadian arctic. Remote Sensing, 9(5), pp. 442.

SarProZ Development Team, 2017. https://www.sarproz.com.

Shi, J., 2012. Surface deformation of alpine terrain derived by PS-InSAR technique on the Siachen Glacier, Fringe Vol.697, Fringe 2011.

Perissin, D., Wang, Z., and Wang, T., 2013. The sarproz insar tool for urban subsidence/manmade structure stability monitoring in China.

Persson, A., 2010. Evaluation on the effect of glacier retreat for the development of deep seated slope deformation: Aletsch glacier, Switzerland. Department of Geology \& Mineral Resources Engineering.

Yague-Martinez, N., Zan, F. D., and Prats-Iraola, P., 2017. Coregistration of interferometric stacks of sentinel-1 tops data. IEEE Geoscience \& Remote Sensing Letters, PP.99, 1-5.

Ye, Q., Kang, S., Chen, F., and Wang, J. 2006. Monitoring glacier variations on geladandong mountain, central Tibetan plateau, from 1969 to 2002 using remote-sensing and gis technologies. Journal of Glaciology, 52(179), pp. 537-545. 